\title{
Perspectives on gender parity in bioanalysis: an interview with Binodh DeSilva
}

\author{
Binodh DeSilva*,1 \\ ${ }^{1}$ Head, Analytical Strategy \& Operations, Bristol-Myers Squibb, New Brunswick, NJ 08903, USA \\ *Author for correspondence: binodh.desilva@bms.com
}

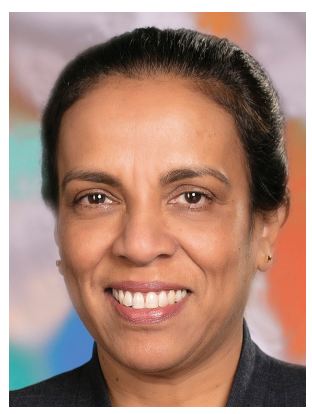

\begin{abstract}
Biography:
Binodh DeSilva, PhD Vice President Analytical Strategy \& Operations at BristolMyer Squibb (BMS) Company in New Brunswick, NJ, USA. She is responsible for leading the regulated analytical (small and large molecule), microbiology and industrial hygiene laboratories as well as the Chemistry, Manufacturing \& Controls $(\mathrm{CMC})$ regulatory document management functions in Product Development. She received her Bachelor's in Analytical Chemistry from the University of Colombo, Sri Lanka in 1987, and a PhD in Chemistry (Bioanalytical) in 1994 from the University of Kansas. She was a Post-Doctoral Research Associate in the Pharmaceutical Chemistry Department at the University of Kansas from 1994 to 1995. She was at Procter \& Gamble Pharmaceuticals, Norwich, NY, USA, from 1995 to 2001 and at Amgen, Thousand Oaks, CA, USA leading the bioanalytical team from 2001 to 2010. She joined BMS in November of 2010. Dr DeSilva is the Past President of the American Association of Pharmaceutical Scientists. In addition, she is a member of the American Chemical Society, Association for Women in Science, and the Health Care Business Women's Association NY/NJ metro chapter.
\end{abstract}

Accepted for publication: 12 March 2019; Published online: 18 April 2019

What advice would you give to young women hoping to embark on a career in the field?

I work for the pharmaceutical industry. My strongest advice would be to understand artificial intelligence, machine learning and statistics in addition to the areas of research. In the era of big data, knowing how to use the data to develop solutions is a great knowledge to have. In addition, a cross-functional understanding of the adjacent areas of research to your research is of critical value. It is imperative that we know how our fields of research impact the global drug development paradigm. It is essential that we understand the fiscal responsibilities of a scientist, how to manage the return on investment in the activities we embark on. Most graduates who enter the workforce in the areas of research are not aware of the business and the financial acumen of the industry.

\section{How can mentors help women in their career development?}

Not all mentors are created equal. I suggest that you have multiple mentors - some situational and others can be more stable. As we progress through our careers, we need to have some confidant or mentor that we can easily pick up the phone and ask a question very candidly. This takes time to develop and nurture. Mentors can help with navigating situations that are complex. Many mentors have had the experience and they can give you tips to handle the situations. Mentoring is a two-way street, many young professionals want answers, but they also need to be prepared to discuss what is important to them.

\section{What advice would you give to women hoping to pursue senior-level scientific positions?}

I personally consider it an honor and privilege to be part of a senior team, be it scientific or managerial. It is necessary to understand that there is a huge element of giving rather than taking in these positions. There is coaching, teaching and empowering others. 
Being comfortable working in a matrix environment is necessary. We must be comfortable of letting go, at this stage in the career while it is tempting to go the laboratory and run that one experiment, it is not practical or possible, and one has to depend on others to provide the necessary data for the problem.

It is necessary to provide a psychologically safe (inclusive) environment for discussing different opinions, viewpoints and debate. Be comfortable with ambiguous or situations where we need to make decisions with limited datasets.

\section{What are the most valuable skill sets women/diversity bring to an organization?}

The multitude of solutions, ideas, thoughts and discussion topics is invaluable to a problem-solving situation. Diversity of the group brings these to the table. Women are more apt to find a consensus solution to difficult issues.

Empathy is a very valuable skill when we have to work in situations that are not black and white. Women in general listen more carefully before trying to solve the issues and give answers. Many women mentors I have had provide/guide you through the issue, they then sit back and let me solve it. This has a tremendous benefit since I felt a sense of accomplishment.

\section{What are the main motivations for you in the industry as a woman?}

Being part of a big picture to solve critical scientific problems. I am motivated by the opportunity that is before us such as, the complexity of the pharmaceutical modalities, challenges of delivery and the patients who benefit from the medicines I am part of.

\section{Who or what inspired you to pursue a scientific career?}

Both my parents were science teachers and from a young age I was exposed to science. My mother was the first role model/biggest cheerleader for me. There was also a professor during my undergraduate years that truly motivated me to do chemistry and pursue higher education.

\section{How do you mange work/life balance in your busy schedule \& what advice would you like to give to young women who are starting their careers?}

I have to admit that I was not good at this when I began my professional life. I was working long hours, putting $100 \%$ of my energy 'doing things perfect' both at work and home. This was not sustainable. Time management was key. One of the hardest things for me was delegating tasks. It was much easier for me to do it rather than teach someone to do it or more accurately, not knowing if they will do it 'right'. It is okay to make mistakes, learn from these and move on.

I am a very organized individual and have multiple to do lists. I had to learn to prioritize my activities both at home and work. I use only one calendar now. This has helped me see the full picture of the activities I have to get done.

I have also learned to ask for help. There are a lot of people who have strengths that complement my development opportunities. I seek them out so that I can also sharpen my skills but most importantly to ask for assistance.

It has taken me time to learn how to manage my energy versus time. Time is a constant and sometimes when we are flustered and stressed out we waste more time than necessary. Take time for yourself. It is easier said than done.

\section{How would you like to inspire the next generation of girls/women in STEM?}

Today's women are more connected to the world than when I was growing up. Hence, any activities that go beyond 'what's in it for me' is how I would inspire the next generation women in STEM.

Disclaimer

The opinions expressed in this interview are those of the interviewee and do not necessarily reflect the views of Future Science Group.

Financial \& competing interests disclosure

The author has no relevant affiliations or financial involvement with any organization or entity with a financial interest in or financial conflict with the subject matter or materials discussed in the manuscript. This includes employment, consultancies, honoraria, stock ownership or options, expert testimony, grants or patents received or pending, or royalties.

No writing assistance was utilized in the production of this manuscript. 